\title{
Isolation of $\alpha$-cellulose from Oil Palm Waste Biomass as a Raw Material for Nanocrystalline Cellulose (NCC)
}

\author{
Fitriani Kasim ${ }^{\#}$, Khaswar Syamsu*, Dwi Setyaningsih", Prayoga Suryadarma*, Sudirman ${ }^{+}$ \\ \# Department of Agricultural Product Technology, Andalas University, Limau Manis Padang, West Sumatera, Indonesia \\ E-mail: fitri123mabit@gmail.com
}

* Departement of Agricultural Industrial Technology, Bogor Agricultural University, West Java, Indonesia E-mail:khaswars@yahoo.com

\footnotetext{
${ }^{+}$Science and Advanced Material Technology Center - National Nuclear Energy Agency, Center for Research in Science and Technology Area, Serpong, South Tangerang, Indonesia

E-mail: sudirman@batan.go.id
}

\begin{abstract}
Oil Palm Empty Fruit Bunches (OPEFB) and mesocarp can mainly be used as a raw material for nanocrystalline cellulose (NCC), which was previously converted into $\alpha$-cellulose. Although this biomass is abundant, it needs to be observed that which part of the OPEFB and mesocarp are more suitable to be used as a raw material for NCC in terms of the characteristics of $\alpha$-cellulose, especially the degree of crystallinity. To isolate $\alpha$-cellulose, the lignocellulose material was dissolved into acid, delignified to remove lignin and bleached, then dissolved it with $\mathrm{NaOH} \mathrm{17.5 \%}$. The samples were then analyzed for the composition of fiber chemicals, determined the yield of $\alpha$-cellulose, degree of crystallinity (XRD), functional groups (FTIR) and surface morphology (SEM). From the observation, it is known that OPEFB fibers have relatively higher cellulose levels the mesocarp fibers. From the visual appearance, $\alpha$ cellulose color of OPEFB is whiter than the mesocarp. Comparatively, the yield of $\alpha$-cellulose and the degree of crystallinity of fiber and $\alpha$-cellulose OPEFB are higher than the mesocarp. The observation of functional groups showed that there was a difference between fiber and $\alpha$-cellulose, but there was no difference between $\alpha$-cellulose and OPEFB and mesocarp. The observation of the surface morphological structure of $\alpha$-cellulose shows that the OPEFB has a more unified structure by forming regular microfibrils, while the mesocarp surface is irregular. Based on the analysis, it can be concluded that OPEFB fibers are more suitable to be used as raw material for nanocrystalline cellulose than mesocarp fibers.
\end{abstract}

Keywords - oil palm empty fruit bunches fiber; mesocarp fiber; delignification; surface morphology; functional group.

\section{INTRODUCTION}

Nanocrystalline cellulose (NCC), also known as cellulose nanocrystals (CNCs), nanowhiskers, nanorods, rod-like cellulose crystals, whiskers, rod-like cellulose, microcrystals $[1,2]$, is in the form of elongated crystalline rods [ 3], 5-70 $\mathrm{nm}$ wide and $100 \mathrm{~nm}$ to several micrometers long [1], with limited flexibility, compared with the nanofiber cellulose (NFC) because of a lack of an amorphous region [2].

Compared with cellulose fibers, NCC has more advantages, such as the nanoscale dimensions, specific strength, high modulus, high surface area, and unique optical properties [4]. Besides, NCC has a relatively low density, a high aspect ratio [5], and modifiable surface properties due to a reactive side $-\mathrm{OH}$ group. The physicochemical properties of NCC can be used in various fields such as the production of regenerative medicine, coatings, adhesives, filtration membranes, and composite materials, printing applications, and optical applications [6].

To produce NCC, the cellulose is derived from wood, cotton, ramie, wheat straw, mulberry bark, tunicin, algae, and bacteria [1]. In Indonesia, a natural fiber from oil palm processing industry waste (Elaeis guineensis Jacq.) is considered to have high potential as Indonesia is the largest global producer of crude palm oil (CPO) and crude palm kernel oil (CPKO). In 2013, the CPO and CPKO production reached 29.5 and 3.9 million tons respectively. The total area of palm plantation in 2015 was 9.2 million ha, producing 31.5 million tons of CPO. The CPO production is estimated to exceed 40 million tons by 2020 , and 60 million tons by 2030. According to the Presidential Regulation Number 28 of 2008 and the Ministerial Regulation of the Ministry of Industry Number 13 of 2010, the oil palm processing industry is a national industry to develop on priority because 
raw material for the industry is abundant in Indonesia [7]. Simultaneously, CPO and CPKO production also create a huge amount of waste, and natural fibers produced from this waste great potential and must be explored.

Based on the estimation and conversion of oil palm area in 2015 amounting to 9.2 million ha, with the assumption of oil palm productivity of 25 tons of fresh fruit bunches (FFBs)/ha/year, the TBS will be 230 million tons/year. Of the FFCs produced during FFB-CPO processing, if oil palm empty fruit bunches (OPEFBs) solid waste comprises $23 \%$ and fruit fiber (mesocarp) waste comprises $13 \%$, then in 1 year there will be 52.9 million tons of OPEFB waste and 29.9 million tons of FFB waste. This massive amount of waste demands effective alternative utilization to reduce the waste and minimize exploitation of forests for natural fiber for the industry. This waste can be used to produce NCC as a low-cost filler in the manufacture of polymer composites.

To obtain NCC, cellulose is first converted to $\alpha$-cellulose (a long chain insoluble cellulose, Figure 1) in $17.5 \% \mathrm{NaOH}$ solution or a strong alkaline solution with a degree of polymerization (DP) between $600-1500$. The DP is also used as a predictor and /or determinant of cellulose purity level [8]. Generally, multistage pulping is used to isolate the $\alpha$-cellulose. The lignocellulose material is dissolved in acid before is it subjected to delignification to remove and bleach the lignin. B- and $\gamma$-cellulose are then separated by dissolving $\alpha$-cellulose in $17.5 \% \mathrm{NaOH}$.

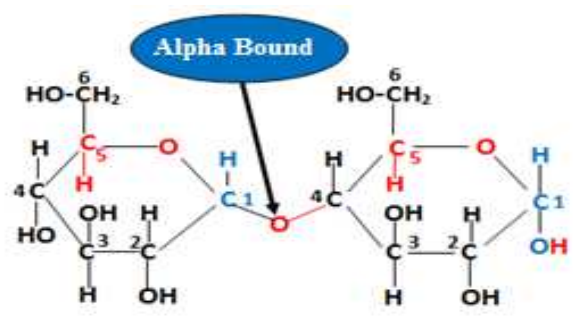

Fig. $1 \alpha$-cellulose [8]

Previous research on $\alpha$-cellulose isolation has been carried out, both on Spruce wood [9], oil palm empty fruit bunches and dried jackfruit leaves [10], sugar palm bunches [11]. However, studies of $\alpha$-cellulose isolation from oil palm biomass solid waste, namely oil palm empty fruit bunches and mesocarp, as raw material for nanocrystalline cellulose have not been carried out and there is no information about this. Though oil palm empty fruit bunches (OPEFB) and mesocarp fibers are very abundant and can be used as a source of fiber for industrial needs, to reduce the excessive exploitation of forests to meet the needs of natural fibers.

This study aims to determine which oil palm biomass waste between OPEFB and mesocarp which is more suitable to be used as raw material for nanocrystalline cellulose in terms of the characteristics of $\alpha$-cellulose, especially the degree of crystallinity.

\section{MATERIAL AND METHOD}

\section{A. Preparation and Characterization of Raw Materials}

OPEFB and mesocarp fibers were initially dried in sunlight until the moisture level is reduced to approximately $10 \%$. They were then mashed in a hammer mill and sieved using a multilevel sieve to obtain fibers with a mesh size of 40 .

\section{B. Analysis of Chemical Components}

The following chemical components of the fibers were analyzed: water content (using the oven method), holocellulose, cellulose, and hemicellulose (TAPPI T257 om-85); lignin (TAPPI T222 om-88); ash level (TAPPI T211 om-85), and extractive substances (TAPPI T264 om-88). The degree of crystallinity was determined by X-ray diffraction (XRD), functional groups were determined by Fourier to transform infrared (FTIR) spectroscopy, and surface morphology was analyzed by scanning electron microscopy (SEM).

\section{Isolation of $\alpha$-Cellulose and Characterization}

$\alpha$-cellulose was isolated using the method specified by Sumaiyah et al. [11]. 75 grams of OPEFB and mesocarp fibers were inserted into a glass beaker, and then $1 \mathrm{~L}$ of $3.5 \%$ $\mathrm{HNO}_{3}$ mixture and $10 \mathrm{mg}$ of $\mathrm{NaNO}_{2}$ were added. The beaker was heated on a hot plate at $90{ }^{\circ} \mathrm{C}$ for $2 \mathrm{~h}$. The contents were then filtered, and the pulp was washed to obtain a neutral filtrate, which was later dissolved in a $750 \mathrm{ml}$ solution containing $2 \% \mathrm{NaOH}$ and $2 \% \mathrm{Na}_{2} \mathrm{SO}_{3}$ at $50{ }^{\circ} \mathrm{C}$ for $1 \mathrm{~h}$ before being filtered. The dregs were washed until they reached a neutral $\mathrm{pH}$. Bleaching was then performed using $250 \mathrm{~mL}$ of $1.75 \% \mathrm{NaOCl}$ solution at boiling temperature for $30 \mathrm{~min}$. The contents were filtered and the pulp was washed until it reached a neutral $\mathrm{pH}$. Purification of $\alpha$-cellulose was performed using $500 \mathrm{~mL}$ of $17.5 \% \mathrm{NaOH}$ solution at $80{ }^{\circ} \mathrm{C}$ for $30 \mathrm{~min}$. The contents were re-filtered, and the filtrate was washed until it reached a neutral $\mathrm{pH}$. The bleaching of the filtrate with $10 \% \mathrm{H}_{2} \mathrm{O}_{2}$ at $60{ }^{\circ} \mathrm{C}$ for $5 \mathrm{~min}$, then dried in an oven at $70{ }^{\circ} \mathrm{C}$ for $1 \mathrm{~h}$, and stored in a desiccator. The $\alpha$ cellulose yield obtained was determined, in addition, to see the degree of crystallinity (XRD), functional groups (FTIR) and surface morphology (SEM).

\section{Yield}

The $\alpha$-cellulose yield was calculated as the ratio between the mass of the product and the initial mass (per dry weight or wet weight.

$$
\text { Yield }(\%)=\frac{\text { arallowe waght }}{\text { antialnbar wight }} \times 100 \%
$$

\section{E. Degree of Crystallinity (by XRD)}

The degree of crystallinity was measured by XRD (Maxima X XRD-7000 Shimadzu, Japan) with a lean angle approximately $2 \theta=00^{\circ}-40^{\circ}$ and in steps of $2 \theta=0.02^{\circ}$. The analysis was conducted using $\mathrm{Cu} \mathrm{K \alpha}$ irradiation at voltage $40 \mathrm{kV}$ voltage, a current of $30 \mathrm{~mA}$ and a wavelength of $1.54 \AA$ 我 wave length.

\section{F. Functional Groups (FTIR)}

An FTIR Perkin Elmer Frontier Spectrometer with a wave number of $400-400 \mathrm{~cm}^{-1}$ was used to detect the functional groups in $\alpha$-cellulose fibers and $\alpha$-cellulose of OPEFB fibers, and mesocarp. 


\section{G. Surface Morphology (SEM)}

The morphology of the OPFEB and mesocarp fiber surfaces and of OPEFB and mesocarp $\alpha$-cellulose was observed using SEM (Hitachi S-3400, Hitachi Ltd, Japan) The specimens were prepared by placing OPEFB and mesocarp fibers and OPFEB and mesocarp $\alpha$-cellulose on double sided carbon in high vacuum mode.

\section{RESULT AND DISCUSSION}

\section{A. Chemical Composition of Oil Palm Waste Biomass}

Table I shows the chemical composition of OPEFB fibers and mesocarp. OPFEB fibers contained higher cellulose, and lower lignin with extractive substance levels (52.96\%, $17.25 \%$ and $7.09 \%$ respectively) as compared with the mesocarp.

Cellulose, a linear homopolymer consisting of $\beta$-D glucopyranose connected through $(1 \rightarrow 4)$ [12], [13], is a major component of wood. Cellulose is the raw material in $\alpha$-cellulose isolation. $\alpha$-cellulose is a long chain cellulose that is insoluble in $17.5 \% \mathrm{NaOH}$ solution or a strong alkaline solution with a 600-1500 DP. $\alpha$-cellulose is used as a predictor and /or determinant of the cellulose purity level [8]. Lignin comprises macromolecules that have different structures compared with polysaccharides as they comprise aromatics from phenylpropane units. Morphologically, the lignin is an amorphous compound found in the middle lamellae and in the secondary wall [14]. It is small, but it has the ability to interfere with cellulose extraction. It also comprises certain extractive components, such as resin, wax, fatty acids, and oil residues, which are flammable, have a distinctive odor, and block the pulping process.

TABLE I

Chemical COMPosition Of OPEFB AND Mesocarp Fibers

\begin{tabular}{|l|c|c|}
\hline \multicolumn{1}{|c|}{ Chemical composition (\%) } & OPEFB fibers & Mesocarp \\
\hline Water Content & 7.27 & 9.76 \\
\hline Solubility in: & & \\
\hline NaOH 1\% & 25.58 & 29.20 \\
\hline Hot Water & 8.55 & 6.48 \\
\hline Cold Water & 5.08 & 3.44 \\
\hline Ethanol Benzene & 7.09 & 8.71 \\
\hline Holocellulose & 70.52 & 56.57 \\
\hline Cellulose & 52.96 & 46.36 \\
\hline Hemicellulose & 17.57 & 11.21 \\
\hline Lignin & 17.25 & 32.61 \\
\hline Ash & 3.25 & 5.12 \\
\hline Volatile Substance & 75.23 & 73.02 \\
\hline
\end{tabular}

\section{B. $\alpha$-Cellulose Yield}

The OPEFB $\alpha$-cellulose yield was higher compare to mesocarp ( $\alpha$-cellulose yield, as shown in Table II). The conversion of fibers to $\alpha$-cellulose is done through multistage pulping, which breaks down and eliminates amorphous components, such as lignin, hemicellulose, and other substances, in the form of micromolecules, leaving a chain of cellulose that is resistant to and insoluble in $17.5 \%$ $\mathrm{NaOH}$, known as $\alpha$-cellulose. The higher the amorphous content shown by lignin and hemicellulose levels, the more the number of parts that will be broken down and removed in the pulping and bleaching processes, leaving a lesser amount of $\alpha$-cellulose content. As a result, the yield obtained as a result of the comparison of $\alpha$-cellulose with the initial sample weight will be smaller. This description is supported by the data on chemical components of OPEFB fibers, which have crystalline parts larger in the form of cellulose and amorphous with smaller amounts compared to the mesocarp.

TABLE II

OPEFB AND MESOCARP FIBERS A-CELLULOSE YIELD

\begin{tabular}{|l|c|c|c|}
\hline \multirow{2}{*}{ Source } & \multicolumn{3}{|c|}{$\alpha$-Cellulose yield (\%) } \\
\cline { 2 - 4 } & 1 & 2 & Average \\
\hline OPEFB & 31.60 & 33.35 & 32.48 \\
\hline Mesocarp & 14.95 & 17.07 & 16.01 \\
\hline
\end{tabular}

\section{Degree of Crystallinity (X-Ray Diffraction test, XRD)}

Table III shows the degrees of crystallinity of fibers and $\alpha$-cellulose. We found that the degree of crystallinity of raw material was lower than that of $\alpha$-cellulose, regardless of being derived from OPEFB and mesocarp. The degree of crystallinity of raw materials is lower because of the effect of removal of amorphous content including lignin and hemicellulose, during acid hydrolysis when isolating $\alpha$ cellulose isolation [15], [16]. When the amorphous substances are released in dissolution during acid hydrolysis, the individual crystals are released, thereby, increasing the degree of crystallinity [17].

TABLE III

Crystallinity Of OPEFB AND MesocARp Fibers AND A-CELlulose

\begin{tabular}{|l|c|}
\hline \multicolumn{1}{|c|}{ Source } & Degree of crystallinity (\%) \\
\hline OPEFB Fiber & 18.78 \\
\hline Mesocarp Fiber & 16.34 \\
\hline OPEFB $\alpha$-Cellulose & 31.17 \\
\hline Mesocarp $\alpha$-Cellulose & 25.97 \\
\hline
\end{tabular}

In addition, by the elimination of amorphous substances, cellulose chains become more solid, eventually increasing the degree of crystallinity. Therefore, a high degree of crystallinity can be perceived as solid molecule structure arranged in rows [18]. The X-ray diffactogram of the crystalline polymers show sharp peaks, whereas the amorphous polymer shows widening peaks. The crystallinity degree of fiber and OPEFB $\alpha$-cellulose, which is higher than that in mesocarp, shows that the fiber of OPEFB is a better raw material for NCC isolation, which requires a higher degree of crystallinity. Besides a higher yield and degree of crystallinity possessed by the OPEFB fibers and $\alpha$-cellulose had a brighter visual appearance. The mesocarp $\alpha$-cellulose was rather dark because of high lignin content and extractive substance levels (solubility in ethanol benzene) compared with OPEFBs (Figure 3).

\section{Functional Groups (FTIR)}

FTIR analysis is conducted to identify the functional groups in the chemical structures of substances such as alkanes, esters, aromatics, and alcohol [19]. Table IV and Figure 4 show the results of FTIR analysis in OPEFB and mesocarp fibers and $\alpha$-cellulose. The OPEFB and mesocarp $\alpha$-cellulose show peaks of 3154 and $3148 \mathrm{~cm}^{-1}$, respectively that are associated with vibration stretching of amine groups $-\mathrm{NH}$. 


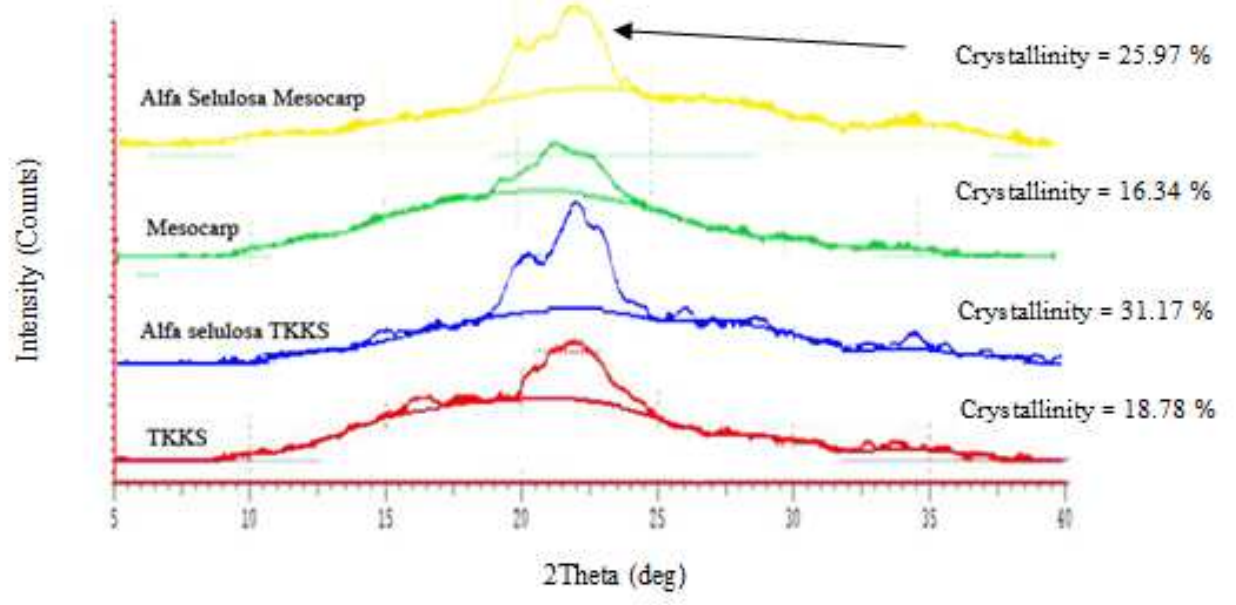

Fig. 2. X Ray Diffractogram

Cellulose is formed by three functional groups: $\mathrm{C}-\mathrm{O}$, $\mathrm{OH}$ and $\mathrm{C}-\mathrm{H}$. The peaks in OPEFB and mesocarp fibers with wave numbers of approximately 3447 and $3391 \mathrm{~cm}^{-1}$, respectively, indicate the presence of $-\mathrm{OH}$ groups. The $-\mathrm{OH}$ groups in cellulose make the cellulose surface hydrophilic.

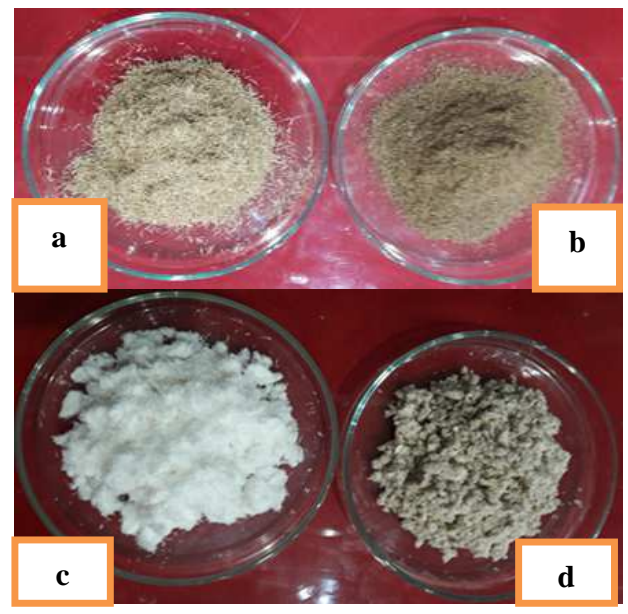

Fig. 3 Visual Appearances of Samples (a.) OPEFB Fibers, (b.) Mesocarp (c.) OPEFB $\alpha$-cellulose, (d.) Mesocarp $\alpha$-cellulose

This group interacts with $-\mathrm{O},-\mathrm{N}$, and $-\mathrm{S}$ to form hydrogen. The $-\mathrm{OH}$ groups in $\alpha$-cellulose are substituted by $-\mathrm{N}$, acid hydrolysis using $\mathrm{HNO}_{3}$, resulting in fewer -OH groups due to the elimination of abundant substance and amorphous cellulose (delignification and bleaching). Amorphous cellulose is a hydrophilic part of cellulose with excessive -OH groups, hence, this part has strong affinity toward any substances that contain $-\mathrm{OH}$, especially water [19], [20]. In the $\alpha$-cellulose of OPEFB and mesocarp, peaks 3154 and $3148 \mathrm{~cm}^{-1}$ that are associated with vibration stretching of amine groups $-\mathrm{NH}$.

The $\mathrm{C}-\mathrm{H}$ functional group was found in both OPEFB and mesocarp fibers and OPEFB and mesocarp $\alpha$-cellulose with peaks at wave numbers of 2924, 2943, 2901 and $2897 \mathrm{~cm}^{-1}$, respectively. Likewise, the $\mathrm{C}-\mathrm{O}$ functional groups were found at peaks wave numbers 1063,1033 , and $1030 \mathrm{~cm}^{-1}$. The existence of $\mathrm{C}-\mathrm{H}$ and $\mathrm{C}-\mathrm{O}$ functional groups indicate the presence of cellulose in all samples, whereas the presence of lignin is characterized by $\mathrm{C}=\mathrm{C}$ the functional group at peaks with wave numbers 1624, 1512, 1597 and $1589 \mathrm{~cm}^{-1}$, respectively. In OPEFB and mesocarp $\alpha$-cellulose, the $\mathrm{C}-\mathrm{Cl}$ functional group was found at peaks with wave numbers 665 and $663 \mathrm{~cm}^{-1}$, respectively. This indicates the binding of $\mathrm{Cl}$ from $\mathrm{NaOCl}$ reagent in the sample used in the bleaching process during $\alpha$-cellulose isolation.

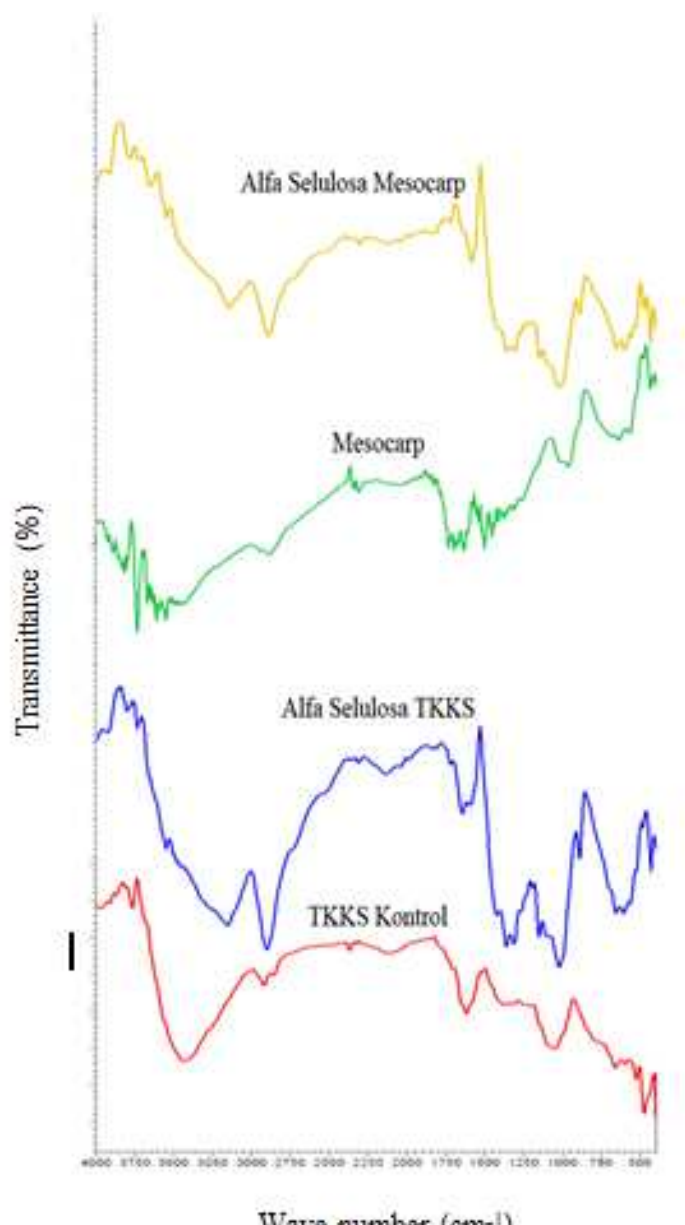

Fig. 4. FTIR Spectra 
TABLE IV

Positions Of Peaks And Functional Group Markers In Opefb And Mesocarp Fibers AND A-Cellulose

\begin{tabular}{|c|c|c|c|c|c|c|c|c|c|}
\hline Treatment & $\begin{array}{l}\mathrm{O}-\mathrm{H}^{[21]} \\
\text { Water } \\
\text { stretch } \\
\left(\mathrm{cm}^{-1}\right)\end{array}$ & $\begin{array}{l}\mathrm{N}-\mathrm{H}^{[22]} \\
\text { Amide } \\
\text { stretch } \\
\left(\mathrm{cm}^{-1}\right)\end{array}$ & $\begin{array}{l}\mathrm{C}-\mathrm{H}^{[22]} \\
\text { Alkane } \\
\text { stretch } \\
\left(\mathrm{cm}^{-1}\right) \\
\end{array}$ & $\begin{array}{l}-\mathrm{C} \Xi C-{ }^{[22]} \\
\text { Alkyne } \\
\text { Stretch } \\
\left(\mathrm{cm}^{-1}\right)\end{array}$ & $\begin{array}{l}\mathrm{C}=\mathrm{C}^{[22]} \\
\text { Aromatic } \\
\text { stretch } \\
\left(\mathrm{cm}^{-1}\right)\end{array}$ & $\begin{array}{l}-\mathrm{C}-\mathrm{H}^{[22]} \\
\text { Alkane } \\
\text { bending } \\
\left(\mathrm{cm}^{-1}\right)\end{array}$ & $\begin{array}{l}\mathrm{C}-\mathrm{N}^{[22]} \\
\text { Amine } \\
\text { stretch } \\
\left(\mathrm{cm}^{-1}\right)\end{array}$ & $\begin{array}{l}\mathrm{C}-\mathrm{O}^{[22]} \\
\text { Ester } \\
\text { stretch } \\
\left(\mathrm{cm}^{-1}\right)\end{array}$ & $\begin{array}{l}\mathrm{C}-\mathrm{Cl}^{[22]} \\
\text { Alkyl Halide } \\
\text { stretch } \\
\left(\mathrm{cm}^{-1}\right)\end{array}$ \\
\hline OPEFB fiber & 3447 & - & 2924 & 2113 & 1624 & - & - & 1063 & - \\
\hline Mesocarp fiber & 3391 & - & 2943 & 2115 & 1512 & - & - & 1033 & - \\
\hline OPEFB $\alpha$-ellulose & - & 3154 & 2901 & - & 1597 & 1367 & 1319 & 1030 & 665 \\
\hline Mesocarp $\alpha$-cellulose & - & 3148 & 2897 & - & 1589 & 1366 & 1321 & 1030 & 663 \\
\hline
\end{tabular}

\section{E. Surface Morphology by Scanning Electron Microscopy (SEM)}

Figure 5 shows the outer surface of OPEFB, mesocarp fibers and $\alpha$-cellulose. The fibers surface look more compact and solid, as compared to the $\alpha$-cellulose; since, the microfibrils are still intact to each other because of the presence of lignin and hemicellulose components [23]. In $\alpha$ cellulose, the lignin-hemicellulose bond gets broken down and removed by amorphous substances, during the acid hydrolysis multistage pulping. Comparatively, the OPEFB $\alpha$-cellulose had a more regular surface structure and the broken-down fibers formed microfibrils. In addition, on the surface of mesocarp $\alpha$-cellulose looked irregular and rough. Those differences occur due to differences in the degree of crystallinity between OPEFB $\alpha$-cellulose and mesocarp $\alpha$ cellulose (see Table 3).
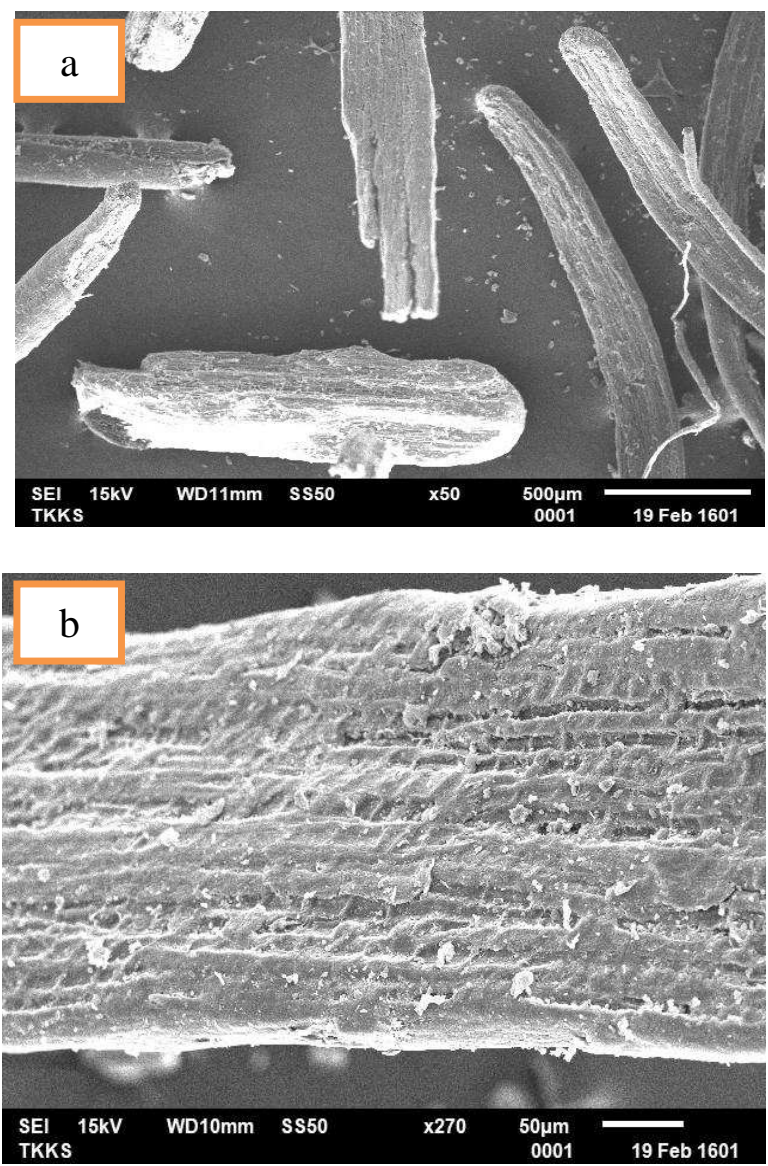
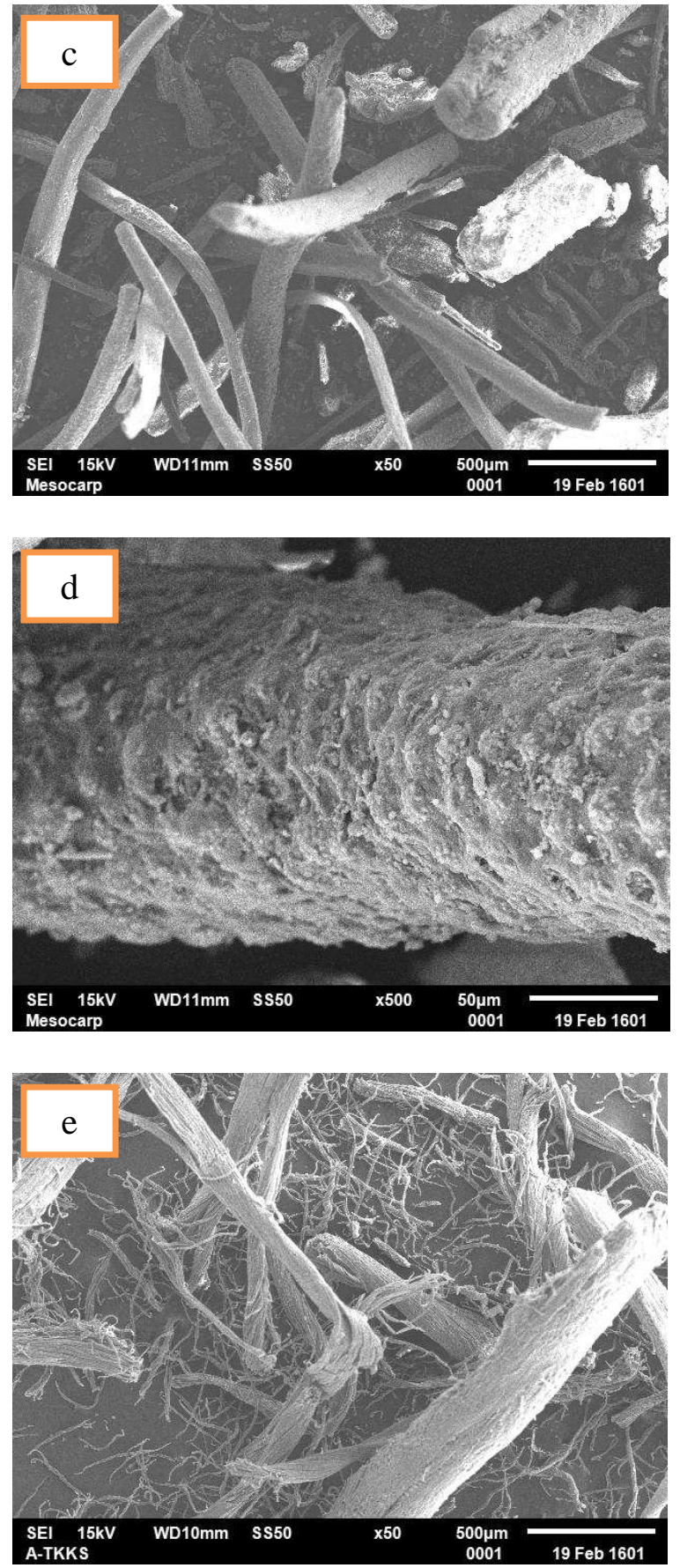

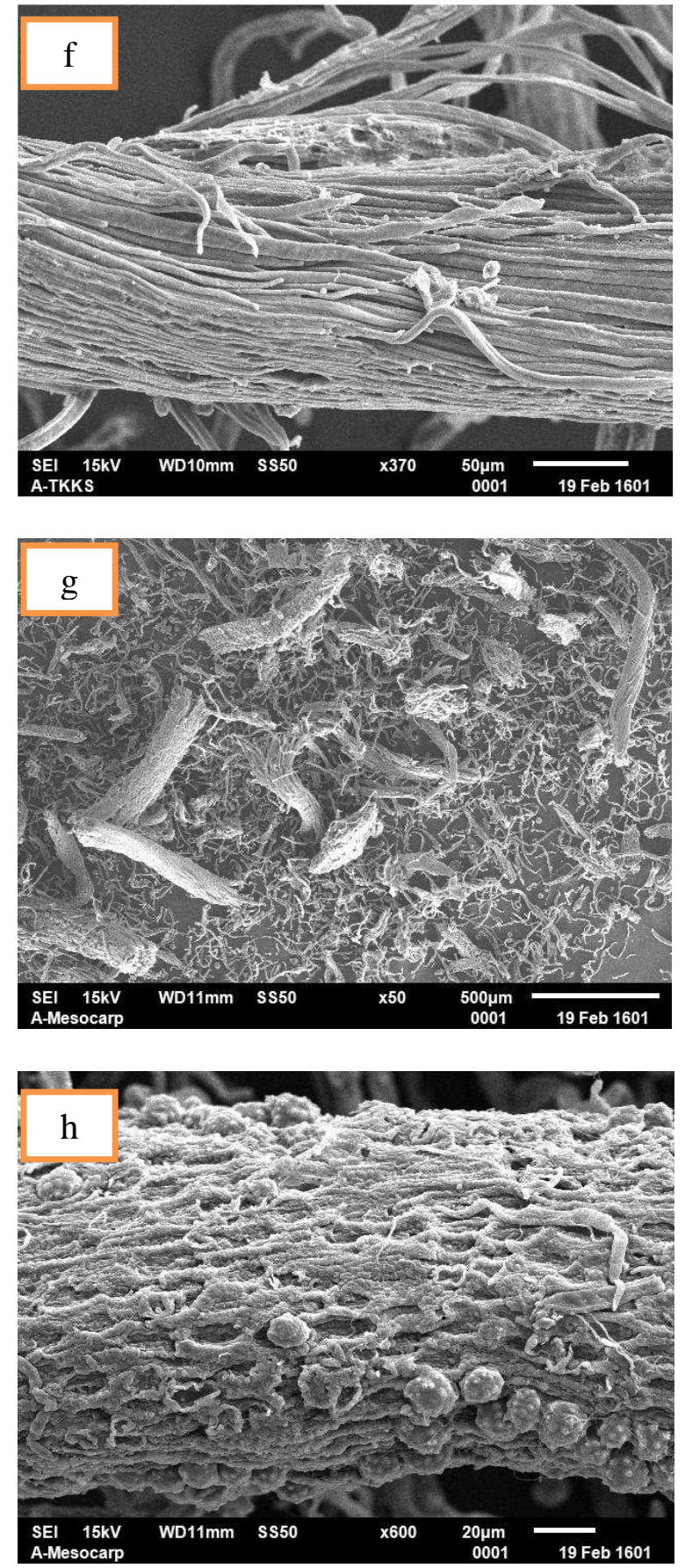

Fig. 5. SEM images (a,b) OPEFB, (c,d) Mesocarp, (e,f) OPEFB $\alpha$-Cellulose, (g,h) Mesocarp $\alpha$-Cellulose

\section{CONCLUSIONS}

Even though mesocarp is equally abundant, its characteristics make it less suitable to be used as a raw material for NCC production. On the other hand, on the basis of their chemical composition, $\alpha$-cellulose yield, degree of crystallinity and surface OPEFB fibers are more suitable as a raw material for NCC production.

\section{ACKNOWLEDGMENT}

Appreciation is expressed to Ministry of Research, Technology, and Higher Education of the Republic of Indonesia that granted Doctoral Dissertation Grants to fund this research (Research contract Number 059/SP2H/LT/DRPM/IV/2017).

\section{REFERENCES}

[1] Klemm D, Kramer F, Moritz S, Lindstrom T, Ankerfors M, Gray D, Dorris A. Nanocelluloses: A New Family of Nature-Based Materials, Angewandte Chemie International Edition. 2011, 50, 5438-5466.

[2] Khalil HPSA, Davoudpour Y, Mustapha A, Sudesh K, Dungani R, Jawaid M. Production and Modification of Nanofibrillated Cellulose Using Various Mechanical Processes: A Review. Carbohydrate Polymers. 2014, 99, 649-665.

[3] Dufresne A, Belgacem MN. Cellulose-reinforced Composites: From Micro-to Nanoscale. Polimeros. 2013, 23, 277-286.

[4] Peng BL, Dhar N, Liu HL, Tam KC. Chemistry and Applications of Nanocrystalline Cellulose and Its Derivatives: a Nanotechnology Perspective. The Canadian Journal of Chemical Engineering. 2011, 89, 1191-1206.

[5] Cao X, Chen Y, Chang PR, Stumborg M, Huneault MA. Green Composites Reinforced with Hemp Nanocrystals in Plastisized Starch. Journal of Applied Polymer Science,. 2018, 109, 3804-3810.

[6] Tang Y, Yang S, Zhang N, Zhang J. Preparation and Characterization of Nanocrystalline Cellulose via Low-intensity Ultrasonic-assisted Sulfuric Acid Hydrolysis. Cellulose. 2013, 21, 335-46.

[7] (2016) Commercial Global Data Research. Study of Market Conditions and Prospects for The Palm Oil Industry and Its Derivatives in Indonesia. [Online]. Available: https://drive.google.com/file/d/0B0KrW40y12QWWWljX3dzTjFMZ Ws/view?pref $=2 \&$ pli $=1$

[8] Nuringtyas, RT. 2010. Carbohydrate. Gajah Mada University Press, Yogyakarta

[9] Stoll M, Fengel D. Studies on Holocellulose and Alpha-cellulose from Spruce Wood using Cryo-ultramicrotomy. Wood Science and Technology. 1977, vol.11, issue 4.

[10] Tristantini D, Dewanti DP, Sandra C. Isolation and characterization of $\alpha$-cellulose from blank bunches of palm oil and dry jackfruit leaves with alkaline process $\mathrm{NaOH}$ continued with bleaching process H2O2. AIP Conference Proceedings [Author(s) Proeedings of The 3RD International Symposium on Applied Chemistry 2017 - Jakarta, Indonesia (23-24 October 2017)].

[11] Sumaiyah, Wirjosentono B, Karsono, Nasution MP, Gea Saharman. Preparation and Characterization of Nanocrystalline Cellulose from Sugar Palm Bunch (Arenga pinnata (Wurmb) Merr.). International Journal of PharmTech Research. 2014, 6, 814-820.

[12] Fahma F, Iwamoto S, Hori N, Iwata T, Takemura A. Effect of Preacid Hydrolysis Treatment on Morphology and Properties of Cellulose Nanowhiskers from Coconut Husk. Cellulose. 2011, 18, 443-450.

[13] Qiu X dan Hu S. "Smart" Materials Based on Cellulose: A review of the Preparations, Properties, and Applications. Materials. 2013, 6, 738-781.

[14] Fengel W, Wegener G. 1995. Wood. Chemical, Ultrastructure, Reactions. Gajah Mada University Press, Yogyakarta

[15] Kumar A, Negi YS, Bhardwaj NK, Choudhary V. "Synthesis and Characterization of Methylcellulose/PVA Based Porous Composite", Carbohydrate. Polymers. 2012, 88, 1364-1372.

[16] Zuliahani A, Hanani ASN, Nadhirah RN, Hazirah A. Isolation and Characterization of Microcrystalline Cellulose (MCC) from Rice Husk (RH) and Kenaf : a Comparison Study. Solid State Science and Technology. 2017, 25, 96-102. ISSN 0128-7389. http://journal.masshp.net

[17] Safinas MSA, Bahar AA, Ismail H. Properties of Kenaf Bast Powder Filled High Density Polyethylene/Ethylene Propylene Diene Monomer Composites. 2013, 8, 2386-2397. DOI 10.15376/biores.8.2.2386-2397

[18] Azubuike CP, Okhamafe AO. Physicochemical, Spectroscopic and Thermal Properties of Microcrystalline Cellulose Derived from Corn Corbs. International Journal of Recycling of Organic Waste in Agriculture. 2012, 1, 1-7. DOI : 10.1186/2251-7715-1-9

[19] Solikhin A, Hadi YS, Massijaya MY, Nikmatin S. Nanostructural, Chemical, and Thermal Changes of Oil Palm Empty Fruit Bunch Cellulose Nanofibers Pretreated with Different Solvent Extractions. Waste and Biomass Valorization. 2017, 1-3. DOI 10.1007/s 12649017-0098-4. 
[20] Khazraji AC, Robert S. Interaction Effects Between Cellulose and Water in Nanocrystalline and Amorphous Regions: A Novel Approach Using Molecular Modeling. Journal of Nanomaterial. 2013, 44.

[21] (2018) The chem.ucla website. [Online]. Available: http://www.chem.ucla.edu/ bacher/General/30BL/IR/ir.html
[22] (2018) The ups website. [Online]. Available: http://www2.ups.edu/faculty/hanson/Spectroscopy/IR/IRfrequencies. html

[23] Mahardika M, Abral H, Kasim A, Arief S, Asrofi M. Production of Nanocellulose from Pineapple Leaf Fibers via High-Shear Homogenization and Ultrasonication. Fibers . 2018,6, 28 